\title{
Prevention of Tuberculosis cross infection; in the process of nursing care
}

\author{
Situmbeko N. Katanekwa', Elizabeth Dahlback ${ }^{2}$ \\ ${ }^{1}$ Karolinska Institutet, Alfred Nobels Alle 23, 23000 SE 14183 Huddinge, Sweden, ${ }^{2}$ Department of Neurobiology, Care Sciences and Society, \\ Division of Nursing, Alfred Nobels Alle 23, 23000, SE 14183 Huddinge, Sweden
}

Nosocomial transmission of TB to healthcare workers (HCWs)is an ever present problem in many health care facilities. The Center for Disease Control and Prevention and the World Health Organization (WHO)have recommended infection control measures such as respiratory isolation rooms with negative pressure for patients with productive cough and use of personal respiratory protective equipment, i.e. respirators. Different infection control measures, usually administrative and engineering simultaneously, have been implemented in industrialized countries and resulted in reduced nosocomial tuberculosis transmission. The implementation of all these measures may be neither feasible nor cost-effective in resourcelimited nations. In particular, engineering measures such as negative pressure isolation rooms with high efficiency particulate air (HEPA) filters maybe unaffordable. However scientifically proved modifications based on Infection Prevention and Control measures can be applied, and studies have proved their efficacy in resource-limited nations. The study used Scientific Articles to; (1) highlight statistics and prevalence of occupationally contracted TB, (2) Discuss the preventive measures and their efficacy from a multidisciplinary perspective and in the nursing care process, in developed and developing countries and (3) Emphasize the use of safe practice in nursing practice.

Key words: Tuberculosis, occupational TB infection, safe nursing practice, infection prevention and control

\section{INTRODUCTION}

Tuberculosis is an occupational disease of HCWs. The infected patient being the primary source of infection must be treated with caution to protect the HCWs, other patients and visitors in various clinical settings. ${ }^{1}$ Nurses and other HCWs in various health care settings encounter different contagious diseases. Miller and colleagues investigated nosocomial transmission of mycobacterium tuberculosis among US HCWs. They found that among HCWs with potential TB exposure, elevated risks were found for nurses. Nurses are at high risk for occupationally contracted TB infection compared to other HCWs because of long working hours, and in developing countries nurses work often in overcrowded healthcare settings. ${ }^{1,2}$ Occupationally contrated TB has led to excessive sick leaves and sometimes deaths of HCWs, reducing the quality of healthcare. ${ }^{2}$
Access this article online

Website:

http://nepjol.info/index.php/AJMS

DOI: http://dx.doi.org/10.3126/

ajms.v7i3.13499

E-ISSN: $2091-0576$

P-ISSN: 2467-9100 
1780 and a rate of 533 deaths per 100,000 persons in New York City in 1868. 5,3

\section{Etiology and transmission}

Tuberculosis is a contagious and predominantly lower respiratory tract infection caused by tubercle bacilli. ${ }^{5,6}$ The principle etiologic agent for TB in humans is Mycobacterium Tuberculosis, an acid fast, aerobic rod. ${ }^{6}$ The acid fast property of mycobacterial cells allows for gramstaining; a diagnostic procedure when TB is suspected. ${ }^{6}$ Other mycobacteria, notably Mycobacterium africanum and Mycobacterium bovis, produce pathology in humans symptomatically similar to M.tuberculosis. ${ }^{6}$ The tubercle bacillus is spread primarily in droplet form through the air, from an actively infected source to a susceptible host. Coughing spreads the bacillus in a wide area through forceful aerosolization and several minutes of singing or talking can aerosolize as many particles as cough. ${ }^{7}$ Thus the nature of the route of transmission can account for the relative increased risk among HCWs working with infected clients and among those in shelters for the homeless or jail holding-cells. ${ }^{8,9}$ Once aerosolized, the droplets must penetrate beyond the ciliated epithelium, into the alveoli for colonization and infection to occur.

Thus, the duration of exposure, number of organisms present in the air, and size of aerosolized droplets are significant indicators of the relative risk of infection.? Most cases of clinically symptomatic and infective TB result from the reactivation of previous asymptomatic chronic infection. Individuals with active PTB may remain infectious and able to spread the disease for an indefinite period. ${ }^{9,6}$

\section{Global disease profile}

The prevalence of Tuberculosis continues to decline in most developed countries throughout much of this century; however in developing countries TB continues to be one of the leading causes of death in patients and HCWs. WHO estimated that 2 million deaths resulted from TB in 2002, and there were 29 deaths per 100,000 population from TB, including TB deaths in people with HIV. ${ }^{10}$ Everyday more than 20,000 people develop active TB and 5000 die from the disease. ${ }^{10}$

\section{Disease profile in swedish history}

The number of deaths from PTB was very high in the first half of the 19th century about 50\%. In Stockholm there is a clear indication that PTB was the greatest killer in the poor areas more so in areas of poor accommodation such as the mining town of Kiruna in 1910. ${ }^{11}$ Generally, housing is an important factor in the communication of TB. Overcrowding was a serious problem in Sweden well into the century; working populations were poorly housed, entire families living in one room. This was true of agricultural laborers and low income groups. The condition of buildings were a negative factor, damp, cold conditions and non-existent ventilation were common, facilitating the survival of the bacilli for long periods in the dust and dirt. ${ }^{11}$ In 1943 the year before introduction of chemotherapy 4,396 people in Sweden died of TB. In 1951 the mortality was less than half this figure. ${ }^{11}$

\section{Present and future}

The incidence of tuberculosis in Sweden is one of the lowest in the world with 6.4 cases per 100,000 residents in $2005 .{ }^{12}$ In 2005 the Smittskyddsinstitutet reported a total number of $575 \mathrm{~TB}$ cases, of which $73 \%$ were born outside Sweden and 27\% indigenous Swedish. In Stockholm a cluster of TB cases of Mycobacterium tuberculosis has been observed since 1996, with 90 cases reported up to 2005 indicating ongoing transmission. ${ }^{13}$ Currently there are no official records of occupationally contracted TB in Sweden.

Disease profile in Zambia and impact on the Zambia nursing workforce

In 2006 the NTCP in Zambia estimated TB incidence at 466 per 100,000 populations, with WHO estimated total number of TB amounting to 64,632 cases. ${ }^{14} \mathrm{~A}$ five-fold increase in TB cases compared to the pre-HIV era. In 2002 WHO data, ranked Zambia, 11th in the world in mortality rate due to TB. HIV/AIDS in Zambia was first diagnosed in 1984. The five-fold increase in TB notification rate since early 1990s is strongly influenced by the occurrence of HIV/AIDS. The Zambia Demographic and Health Survey reported an overall HIV/AIDS prevalence of $15.6 \%$ in 2003 making TB a leading cause of death in people with HIV, cause of $13 \%$ deaths in patients with AIDS. ${ }^{14}$ The Zambian Nurses are greatly affected by rise in the morbidity and mortality of Nurses with TB. Between 1990 and 1996 a total of 114 nurses died of PTB. ${ }^{15}$ The nurses at UTH documented to be on anti-TB treatment in 1999 totaled $20 .{ }^{16}$ A study demonstrated that factors contributing to the occupationally contracted TB included inadequate isolation, precaution and prolonged contact with $\mathrm{TB}$ patients by nurses who worked in medical wards. ${ }^{17}$ Additionally the nurses worked 14 hour night shifts for several consecutive days. ${ }^{17}$ The ICN recommends a 40 hour work week for nurses. ${ }^{17,2}$ At Zambia's UTH and many other hospitals in the country, nurses are required to work 7 continuous night shifts of 14 hours each, (98 hrs). Due to staff shortages, it's common for nurses to work 2 weeks of night rotations per month, for a total of 196 hours of night shift in 2 weeks. ${ }^{17}$ The tubercle bacilli was also isolated on equipment with AFB cultures taken from suction machines, lockers and pillows in the medical wards where the prevalence rate was highest, thus identifying additional exposure risk. 


\section{Relevant studies of occupational TB infection}

The prevalence of TB continues to decline in developed countries in contrast to the rising incidence of TB in developing nations. However the risk for occupationally contracted TB remains for HCWs globally, as patients with active PTB remain contagious for long periods infecting about 10 to 15 people every year. ${ }^{18,10}$ In 1969 , delay in diagnosing a TB case until autopsy resulted in the exposure of 23 employees who required follow-up and treatment. ${ }^{19} \mathrm{It}$ was considered that circulation of airborne droplet nuclei containing Mycobacterium tuberculosis in a central hospital corridor was responsible for the infection of the employees. In 2002 Tipple and colleagues reported a patient with TB who spent three weeks on two general medical wards in the USA, before being placed in respiratory isolation, resulting in the exposure of 261 patients and 784 staff. $^{20}$ Five secondary patients were diagnosed with TB three to six months after exposure to the index patient. In a review of a surveillance report from New York State, the total number of TB notifications declined from 3636 in 1994 to 1434 in 2002 , but cases amongst HCWs increased from $2.5 \%$ to $4 \%$, as indicated by skin testing and other investigations. ${ }^{21}$ In 1999 approximately hundreds of millions of people worldwide were employed in unsafe conditions. Each year, an estimated 160 million new cases of work-related diseases occur and cause 1.1 million deaths from work-related injuries and diseases. ${ }^{22}$ Overcrowded clinics, high patient load and staff shortage increases the risk of occupational TB infection in developing countries.

Inadequate/lack of IPC specialists and independent budgets for IPC units in clinics makes sustaining IPC programmes difficult. ${ }^{22,21}$ Although the incidence of TB may be declining in many countries, the risk of contracting TB in hospitals remains. Mainly due to delayed diagnosis, unsafe practices, poor standards of IPC, inadequate resources, knowledge of practical, appropriate, costeffective and sustainable preventive methods.

\section{Aim}

The aim of this review paper was to use published scientific articles to; (1) highlight statistics and prevalence of occupationally contracted TB in various clinical settings, (2) To discuss the preventive measures and their efficacy from a multidisciplinary perspective and particularly in the nursing care process, in developed and developing countries and, (3) The use of safe practice in nursing practice.

\section{MATERIALS AND METHODS}

\section{Search strategy}

A Literature Search was done on Scientific Articles indexed in Medline/PubMed, Chinahl, and other nursing and medical literature.

\section{Inclusion criteria}

Only articles written in English were selected and most of the articles were written within 1990-2008 time frame. The articles covered issues related to nosocomial and occupationally contracted TB in various clinical settings in developed and developing countries, (America, Europe, Asia and Africa).

\section{Analysis}

The articles were selected using the Search Strategy and inclusion criteria. The articles were analised according to the issues in the Aim of the Literature Review.

\section{RESULTS}

\section{Sample description}

A total number of twelve Scientific Articles and five nurse literature were identified and of those, four Scientific Articles and three nurse literature met the criteria. The review contains 16 selected scientific articles, 4 books, 4 reports and several fact sheets and web based pages.

\section{DISCUSSION}

Multidisciplinary approach to occupational TB infection prevention

Reduction of occupational TB infection requires a multidisciplinary approach, involving the whole healthcare team. The IPC of TB in hospitals is best achieved by three approaches: Administrative, engineering and personal respiratory protection (PRP). ${ }^{23}$ Administrative measures include early investigation, diagnosis and effective treatment of suspected TB patients, with heightened awareness of the diagnosis amongst Nurses and other HCWs. Engineering controls are the facilities in which diagnosed or suspected TB patients are nursed. They include naturally ventilated isolation and respiratory isolation rooms, which are filtered by specific number of air changes per hour, directional airflow; air flowing into the room under negative pressure and as option, HEPA. ${ }^{24}$ PRP refers to the use of filtering masks such as European standard EN 149, which vary from 25\% (FFP1) to 5\% (FFP3) total leakage rate; filtering atleast $95 \%$ of airborne particles. ${ }^{24}$ Risks of transmission are lowered when all measures are combined. To this end an inner city hospital in Atlanta Georgia; revised hospital policy for control of TB in 1992 to include administrative, engineering and PRP measures. ${ }^{25}$ After implementing these measures, the number of TB exposure episodes decreased from 4.4 to 0.6 per month and tuberculin skin test conversion rates amongst $\mathrm{HCW}$ decreased from $3.3 \%$ to $1.7 \%{ }^{25}$

Recent UK guidelines, prepared and published by the NIHCE, recommends that admitted suspected PTB patients are nursed in a single room and should 
remain isolated until they have completed two weeks of treatment. ${ }^{26}$ Patients with suspected multi-drug resistant TB (MDR-TB) should be admitted to a negative-pressure room or transferred to a more suitable facility. ${ }^{27}$ All single rooms used for management of patients with TB should have air flows with 12 air changes per hour and a negative pressure $>0.01$ inches of water compared with adjacent areas, ${ }^{27}$ these rooms should be checked for negative pressure by smoke test or other visual checks daily when occupied by suspected TB patients. A PRP device, or filtering face piece respirator (N95) should be worn by all HCWs entering the room of a patient with suspected or confirmed TB..$^{27}$ Patients themselves can wear a surgical mask or modified filtered oxygen mask. Both masks reduce expulsion of droplet nuclei. ${ }^{27,28}$

\section{Efficacy of control measures (Evidence)}

The provision of isolation facilities represents a significant additional financial burden for all health services. A decision should be made as to whether this provides significant protection for patients and staff. Seventeen Canadian hospitals were monitored to estimate the association between pressure ventilated rooms and tuberculin skin test conversion rates amongst HCWs as a marker for nosocomial transmission. ${ }^{28}$ Although $83 \%$ of respiratory isolation rooms had full mechanical ventilation with separate supply and exhaust systems, only $34 \%$ had directional air flow. Inadequate ventilation of non-isolation patient rooms was closely associated with tuberculin conversion among nursing and other staff. ${ }^{28}$

In a 1000-bed university-affiliated hospital in Georgia, USA, the impact of a dedicated airborne-infection isolation facility with 26 beds was evaluated. The facility reduced the amount of time required in respiratory isolation to exclude $\mathrm{TB}$, and resulted in significant cost savings for the hospital..$^{29}$ Evidence suggest that the use of PRP reduces the risk of exposure if air changes are sub-optimal, but engineering controls; i.e. negative pressure ventilation and HEPA protects everybody in/outside the isolation unit. ${ }^{29}$

\section{Compliance with guidelines}

Even when preventive measures against nosocomial TB are available, compliance with or provision of the measures may be disappointing, therefore regular audits are required to ensure maximal compliance. In a questionnaire survey from 122 Belgian hospitals in 1995, only $84 \%$ of patients with suspected TB were isolated. ${ }^{30}$ Although $96 \%$ of HCWs wore masks when entering a TB patient's room the mask was adequate in only $24 \%$ of these rooms. A minority of hospitals was compliant with guidelines for staff and visitors, i.e. they should wear PRP. In a prospective multi-hospital study of hospital policy for isolation of TB patients in USA, only 15 of 151(11\%), designated negative-pressure rooms fulfilled the criteria at the time of testing and although $94 \%$ of staff used PRP, $65 \%$ did not use PRP correctly.

\section{Implementation of imported IPC guidelines}

Developed countries have established and funded IPC programmes while developing countries face several problems in making IPC programmes robust and sustainable. IPC programmes from developed countries require major infrastructure, expertise and sufficient funding for implementation and may not always be applicable in developing countries. Therefore it's essential that various clinical settings develop own guidelines based on IPC principles, modifying practice within economic climate to fulfill these principles. For instance the recommendation for single patient rooms for confirmed TB cases is difficult to fulfill with a high patient load of presumptive TB cases presenting to acute medicine departments. Therefore confirmed TB patients can be cohort-isolated, while MDR-TB patients are nursed in single cubicles with plenty ventilation before being transferred to specialist departments/hospitals with better facilities. ${ }^{32,33}$ Respiratory protection initiatives that reduce aerosol have been tested. The findings suggest that covering the mouth and nose with a handkerchief or cloth when coughing was effective in reducing aerosol to $0.25 \mathrm{~m}$ and surgical masks effectively reduced aerosol to $0.5 \mathrm{~m} .{ }^{33} \mathrm{In}$ community health centers which are often crowded, patients should be encouraged to bring a hanky that could be used to cover the nose and mouth during coughing in the waiting area. ${ }^{33}$ For confirmed MDR-TB cases, N95 masks are recommended and the members of staff should be instructed in its fitting, proper use and disposal. ${ }^{33}$ These modifications in practice follow the principles of IPC and can be applied to low-resource countries. Therefore principles rather than methods should be considered and guidelines developed accordingly, based on local conditions of the clinical area. A study performed to determine the number of specimens needed to discontinue TB isolation found that a minimum of three was required. ${ }^{33,32}$ Requirement for negative microscopy becomes even more important with MDR-TB when deciding to discontinue isolation. ${ }^{34,35}$

Practices to prevent the spread of TB in nursing practice

To effectively reduce the large number of nurses and other $\mathrm{HCW}$ s with active $\mathrm{TB}$, nurses must play a substantive role in IPC of TB. The continued presence of TB and its resurgence as MDR-TB, means HCWs and Nurses in particular, as they have the initial, sustained client contact at all levels of healthcare, should be invested in IPC of TB. Identifying suspected TB cases during nursing care and recognition of the associated diseases, notably HIV infection and related immunosuppression, assists the 
healthcare team to promptly identify clients who may require TB testing. Studies clearly show that training nurses to identify new hospital admissions likely to have active TB reduces occupationally acquired $\mathrm{TB} .{ }^{36,37} \mathrm{It}$ is recommended that newly admitted patients have a chest $\mathrm{x}$-ray examination done within 48 hours of being hospitalized. ${ }^{36,37}$

Other strategies that limit the spread of infectious disease including TB in healthcare facilities include; in-service education to improve awareness of basic precautions (PRP), risk of transmission and availability of prophylaxis and treatment. ${ }^{37}$ Healthcare facilities must provide $\mathrm{x}$-ray examination as a benefit package to HCWs exposed to TB. If a nurse or doctor has been exposed to a TB case confirmed through chest $\mathrm{x}$-ray and laboratory tests, they should be counseled, given prophylaxis and followed up with $\mathrm{x}$-ray check-up 6 months after exposure. Despite budgetary constraints in healthcare at various clinical settings, especially in developing countries, hospital executives should prioritize allocating reasonable resources for IPC-related supplies, to protect nurses and other HCWs from infection. Certain countries have adopted laws that provide the worker the right to refuse any job assignment that might directly endanger the worker. Such clauses are applied in factories with regard to the use of unsafe machinery but have not included dangerous situations for the HCWs. The right is usually denied safeguarding primarily the right of the patient. ${ }^{38}$ Hospital executives should address the policy for paid time off, especially in situations where a nurse has documented occupationally acquired $\mathrm{TB}$ and needs leave to rest and complete medication until the nurse is no longer contagious. ${ }^{39} \mathrm{It}^{\text {'s }}$ important for nurses to recognize their need to discuss their ethical and health concerns with their supervisors. Nurse Managers should be fully informed of their organization's sick leave policies, evaluate the effectiveness of these policies and develop initiatives for appropriate management of absence due to illness and sick leave after exposure to occupational hazards, for nurses. ${ }^{39}$

Promoting a safe and healthy workplace for nurses Nurses should take the initiative to improve the quality of their work place. Stay abreast of labor rights issues and labor safety regulations related to occupational health and safety for nurses..$^{39,38}$ Healthcare professionals should strive through legislation of a conceptual legal framework for multidisciplinary evaluation, reform and application of hospital policies and procedures related to IPC of TB. ${ }^{39,38}$

\section{CONCLUSIONS}

Nurses should play a substantial role in IPC of TB to protect themselves and their patients during healthcare.
Emphasis should be on use of scientifically proved, practical, sustainable and affordable TB prevention measures, and promoting a safe and healthy workplace for nurses and the healthcare team. Governments, local health authorities, NGOs and health professionals should pool resources together to find a lasting solution against TB.

\section{ACKNOWLEDGEMENTS}

Special thanks to Lusaka schools of Nursing Management, Elisabeth Dahlback (lecturer), Karolinska Institutet, Division of Nursing, Lusaka schools of Nursing, 2006 Intake general nursing (Mkhoma Clan: Little-Ds)and Jiangxi University of TCM, International Education College for all the support and motivation.

\section{REFERENCES}

1. Miller AK, Tepper A and Sieber K. Historical risks of tuberculin skin test conversion among non-physician staff at a large urban hospital. Am J Ind Med 2002; 42(3):228-235.

2. Nurses and Overtime-ICN Fact sheet. International Council of Nurses. 2006 Dec. http://www.icn.ch/matters_overtime.htm Retrieved 2009 May 4.

3. Waksman S: The Conquest of Tuberculosis. Berkeley: University of California Press, 1964.

4. Adams F. The Genuine Works of Hippocrates. Francis Adams Translation. Baltimore: Williams and Wilkins, 1939.

5. Long E. A history of the Theory for Tuberculosis and the Case of Frederic Chopin. Lawrence, KS: University Kansas Press, 1956.

6. Hopewell PC. Tuberculosis and non-tuberculosis mycobacterial infections. In: Stein J, ed. Internal Medicine.3th ed. Boston: Little, Brown and company, 1990, pp. 1534-1552.

7. Benenson AS. ed. Control of Communicable Diseases in Man 15th ed. An official report of the American Public Health Association. Washington D.C: American Public Health Association.

8. Edlin BR, Tokars JL, Grieco MH, Crawford JT, William J, Sordillo EM, et al. An outbreak of multidrug- resistant tuberculosis among hospitalized patients with acquired immunodeficiency syndrome. N Engl J Med 1992; 326:1514-1521.

9. Centers for Diseases Control: Tuberculosis outbreak among persons in a residential facility for HIV-infected persons-San Francisco. MMWR 1991; 40:649-652.

10. StopTB. Fight poverty: Basic facts on TB [online]2002[cited 2009 May 10]. Available from: URL: http://www.stoptb.org/world. tb.day/WTBD 2002/default.asp.

11. Puranen $\mathrm{Bi}$; Tuberculosis. The occurrence and causes in Sweden (1750-2000) [dissertation]. Stockholm Uni., 2003. Available from: www.bikupan.se/tuberculosis/tuberc.html.

12. Romanus V. Selective BCG vaccination in a country with low incidence tuberculosis. Euro Surveill. 2006; 11:14-7.

13. Kan B, Bergren I, Bennet R, Bruchfeld J,Chryssanthou E, Ghebremichael S, et al. Extensive transmission of an isoniazidresistant strain of M.Tuberculosis in Sweden. Int J Tuberc Lung Dis.2008; 12:199-204.

14. The National Tuberculosis and Leprosy Programme. 3th ed, TB Manual 2008. http://www.who.int/hiv/pub/guidelines/zambia_ tb.pdf Retrieved 2009 May 6. 
15. UTH. (1998). Administration records. Lusaka, Zambia: [Unpublished].

16. UTH. (2005). Health Information. Chest clinic (TB Annual reports). Lusaka, Zambia: [Unpublished].

17. Chanda D and Gosnell D. The impact of Tuberculosis on Zambia and the Zambian Nursing Workforce. Online Journal of Issues in Nursing 2006;11(1): Manuscript 3.

18. Stone DS. Health Surveillance for healthcare workers: A vital role for the occupational and environmental health nurse. AAOHN J 2000;48(2):73-79.

19. Ehrenkranz NJ and Kicklighter JL. Tuberculosis outbreak in a general hospital: Evidence for spread of infection. Ann Intern Med 1972; 77:377-382.

20. Tipple MA, Heirendt W, Metchock B, ljaz K, McElroy PD and Andre AM. Tuberculosis outbreak in a community hospital-District of Columbia. MMWR Morb Mortal Wkly Rep 2002;53:214-216.

21. Driver CR, Stricof RL,Granville K, Munsiff SS, Savranskaya $G$, Kearns C, et al. Tuberculosis in healthcare workers during declining tuberculosis incidence in New York State. Am J Infect Control 2005;33(9):519-526.

22. World Health Organization. Occupational health: Ethically correct, economically sound (Fact sheet No 84, Revised June 1999).[cited 2009 May 10]. Available at: http://www.who.int/inffs/en/fact084.html.

23. Schwartman $\mathrm{K}$ and Menzies D. Tuberculosis 11. Nosocomial disease. Can Med Assoc J 1999;161:1271-1277.

24. Curran ET, Hofman PN and Pratt RJ. Tuberculosis and infection control: A review of the evidence. Br J Infect Control 2006; 7:18-23.

25. Blumberg HM, Watkins $\mathrm{DL}$, Berschling JD, Antle A, Moore $\mathrm{P}$, White $\mathrm{N}$, et al. Preventing the nosocomial transmission of Tuberculosis. Ann Intern Med 1995;122:658-663.

26. National Institute for Health and Clinical Excellence. Tuberculosis. Clinical diagnosis and measures for its prevention and control, London. March 2006.

27. Jensen PA, Lambert LA, Indemarco MF and Ridzon R. Guidelines for preventing the transmission of Mycobacterium tuberculosis in healthcare settings. Morb Mort Week Rep 2005;54:1-141.

28. Menzies D, Fanning A, Yuan L and Fitzgerald JM. Hospital ventilation and risk for tuberculosis infection in Canadian healthcare workers. Ann Intern Med 2000;133:779-789.

29. Leonard MK, Egan KB, Kourbatova E, White N, Parrott P, Del Rio $C$, et al. Increased efficiency in evaluating patients with suspected tuberculosis by use of a dedicated airborne infection isolation unit. Am J Infect Control 2006;34;69-72.

30. Ronveaux O, Jans B, Wanlin M and Uydebrouck M. Prevention of tuberculosis in hospitals; a survey of practice in Belgium, 1995. J Hosp Infect 1997;37:207-215.

31. Sutton PM, Nicas M and Harrison RJ. Tuberculosis isolation: Comparison of written procedures and actual practice in three California Hospitals. Infect control Hosp Epidemiol 2000; 21:28-32.

32. Siddiqui AH, Perl TM, Conlon M, Donegan N and Roghmann MC. Preventing nosocomial transmission of pulmonary tuberculosis: When may isolation be discontinued for patients with suspected Tuberculosis. Infect Control Hosp Epidemiol 2002;44:141-144.

33. Mehtar S, Lowbury Lecture 2007: Infection and control strategies for tuberculosis in developing countries-lessons learned from Africa. Journal of Hospital Infection 2008; 69:321-327. [cited 2009 May 9]. Available from: URL:http://www.sciencedirect.com

34. Hannan MM, Azadian BS, Gazzard BG, Hawkins DA and Hofman PN. Hospital infection control in an era of HIV infection and multidrug resistant tuberculosis. J Hosp Infect 2000;44:5-11.

35. Holtz TH, Sternberg M, Kammerer S, Laserson KF, Riekstina V, Zarovska E, et al. Time to sputum culture conversion in Multidrug Resistant Tuberculosis: Predictors and Relationship to treatment outcome. Ann Intern Med 2006;144(9):650-659.

36. Jarvis WR, Bolyard EA, Bozzi CJ, Burwen DR, Dooley SW, Martin LS, et al. Respirators, recommendations and regulations: the controversy surrounding protection of healthcare workers from tuberculosis. Ann Intern Med 1995;122(2):142-146.

37. Special report. TB and health care workers: The challenge for hospitals and their safety directors. Hosp Secur Saf Manage.1994;15(2):5-8.

38. International Council of Nurses. Report on the Regulation of Nursing. Geneva: ICN;1986.

39. Johnson CJ, Croghan E and Crawford J. The problem and management of sickness absence in the NHS: Considerations for nurse managers. J Nurs Manag 2003;11(5):336-342. 